\title{
Health Care Reform in the United States
}

Lawrence O. Gostin

Georgetown University Law Center, gostin@law.georgetown.edu

This paper can be downloaded free of charge from:

https://scholarship.law.georgetown.edu/facpub/759

21 J.L. Med. \& Ethics 6-9 (1993)

This open-access article is brought to you by the Georgetown Law Library. Posted with permission of the author. Follow this and additional works at: https://scholarship.law.georgetown.edu/facpub

Part of the Health Law and Policy Commons, Insurance Law Commons, Public Health Commons, and the Public Policy Commons 


\section{Editorial}

\section{Health Care Reform in the United States}

Lawrence O. Gostin*
A $\mathrm{s}$ this issue of JLME goes to press, the United States is on the verge of national health care . Hillary Rodham Clinton has led a cabitask force, aided by a large health policy committee. The President has not embraced a single-payer health insurance model based on the Canadian system, ${ }^{1}$ or a "pay or play" model that would require employers to provide health insurance or pay into a fund for the uninsured. ${ }^{2}$ Rather, the Task Force is proposing a system of managed competition combined with a global budget.

A description and analysis of the proposals for $\mathrm{Na}$ tional Health Care Reform are contained in the recently published symposium issue of the American Journal of Law \& Medicine. ${ }^{3}$ Here, I present a brief description of the design features and objectives of the reform package for our national and international readers, together with the reasons to support reform of the health care system in the United States.

Managed competition restructures the market for health care services into competing prepaid plans, giving providers built-in incentives to offer a comprehensive benefits package at the lowest cost. The federal government would establish the parameters of the new system through national legislation, with implementation occurring at the state level. State flexibility would become a

"Mr. Gostin is a member of the Presidential Task Force on National Health Care Reform. The findings or conclusions in this paper do not necessarily reflect the views of the Task Force or the American Society of Law, Medicine \& Ethics. hallmark of the new system, with states having considerable leeway in implementation. State flexibility is extremely important because it would not "lock in" all states to a managed competition model. Provided that states comply with all of the federal parameters for providing universal and fair coverage, they might structure their health system in other ways, such as through a single-payer. A large state, for example, might set up a system of managed competition in urban areas, but provide a single-payer in rural areas where effective competition is not feasible.

The basic structure of managed competition would include: (i) a national bealtb board-a quasi-governmental authority established at the federal level that would implement federal standards for the operation of the new system; (ii) bealth alliances-entities established at state level that would purchase health plans on behalf of large numbers of consumers; and (iii) accountable bealth plans (AHPs) - groups of health care providers formed with the purpose of offering a standard benefits package to consumers who join the plan. Health alliances would generally contract with a range of AHPs, including health maintenance organizations, preferred provider groups, and fee-for-service groups.

To be sure, the current American system provides unequalled health care for many who can afford it. But it does so at enormous social and economic costs. The system has failed to provide health care for all with an equitable sharing of burdens and benefits. An estimated 37 million people do not have health care coverage, and 


\section{The Journal of Law, Medicine do Ethics}

many more people are inadequately covered. ${ }^{4}$ Disparities in access to health care have been demonstrated on grounds of socioeconomic status, ${ }^{5}$ race and ethnicity, ${ }^{6}$ and gender. ${ }^{7}$ Severely limiting access to health care deprives individuals of a basic necessity of life. To restrict access to health care can directly affect a person's livelihood, quality of life, and longevity. Denial of health care on any grounds necessarily limits opportunities for a full and decent life. ${ }^{8}$ When access to care is limited, directly or indirectly, according to a person's status, such as being poor, a member of an ethnic minority, a woman, or a person with disabilities, it reinforces deep and persistent inequalities in American society.

The current system has also failed to control escalating costs relative to health care expenditures in other countries. The United States spent more than $\$ 800$ billion on health care in 1992, approximately 13.6 percent of the nation's gross national product (GNP). Health care expenditures are expected to reach $\$ 1.6$ trillion, between 16 and 18 percent of the gross domestic product, by the end of the decade if effective controls are not instituted. ${ }^{9}$ These figures stand in stark contrast to the percentage of the GNP that is devoted to health care in countries such as Canada, Germany, Great Britain, and Japan: they devote from 5.8 percent to 8.7 percent of their GNPs to health care. ${ }^{10}$

The steady increase in health care costs in the United States over the last decade has many detrimental social and economic effects. It contributes to the deficit and to the need for higher taxation; it affects the competitiveness of American business in international markets; and it diverts valuable resources from other social goods such as providing children with education, providing shelter for the homeless, and providing job training for young people.

These economic and social harms to individuals and groups are so fundamental that the nation cannot afford to miss an opportunity to reform the health care system. While it is relatively easy to demonstrate the economic and social harms of the current system, constructing a new one is fraught with complexities and trade-offs. There does not appear to be a clear 'mandate for a particular kind of reform, as there was in the cases of antidiscrimination legislation for African-Americans, women, and persons with disabilities. Any system of comprehensive change will directly affect the interests or preferences of substantial numbers of influential groups-policymakers and academics often prefer a single-payer system to managed competition; insurance companies would feel threatened by a single-payer system; many consumers want an absolute choice of providers; many providers insist on fee-for-service methods of payment; and many middle and upper income taxpayers do not want to bear higher burdens to help pay for health care for poorer people. These ingrained preferences and powerful inter- ests impede reform efforts, leading political analysts to wonder whether health care reform can be enacted at all.

Should Americans support the President's plan? To be sure, managed competition within a budget has never been tried. Some economists predict that affordable high quality care can be obtained through aggressive purchasers acting on behalf of a large number of consumers, meaningful competition among health plans, and a global budget. ${ }^{11}$ Other analysts have argued that managed competition will not work. It is feasible that groups of providers will collude with each other rather than compete. It is also feasible that forces currently pushing health care costs, such as increasingly sophisticated technology and consumer insistence on more services, will continue to keep costs high.

Restructuring the health care system, however, stands a credible chance of slowing the rise in health care costs. If it cannot do so through competition, it can still set a realistic budget and reduce the considerable administrative costs and proliferation of insurers inherent in a traditional indemnity system. More importantly, the President's plan gives states sufficient flexibility to construct a health care system in innovative ways (e.g., authorizing a single-payer) that may do better in saving costs than either the current system or managed competition. Ongoing assessment of a reformed health care system may enable states to choose more efficient ways of providing high quality, affordable care.

Those who oppose managed competition in favor of a single payer system must wrestle with a pragmatic political question. If the plan submitted by the President to Congress is defeated, will the window of opportunity for health care reform be closed? This sobering thought ought not to oblige allegiance to managed competition at any cost. Rather, the reform package should be measured by standards that are at least as compelling as saving money. The ethical values of access, equity, justice, and choice are critical to any decent society seeking to improve the health and well-being of its citizens. The President's plan could provide benefits under most or all of these criteria when compared with the status quo. Much will depend upon the precise provisions that are enacted by Congress.

\section{Access to care}

Five essential national parameters are being contemplated for the federal statute. They are designed to increase access to health care significantly.

First, the health care reform bill would entitle citizens and lawful residents of the United States to a health security card guaranteeing access to an AHP. Second, AHPs would have to be open to all persons who hold health security cards and choose to enroll in the plan, 
subject to space limitations. Health plans would not be permitted to gerrymander their geographic areas to avoid certain populations because of risk profile, race, or socioeconomic status. Third, health care would be portable, with individuals free to move from any job and to any part of the country. Fourth, AHPs would be required to "community rate." They could not establish pre-existing condition clauses, place caps on coverage for any individual or group, or charge higher premiums based upon increased actuarial risks. Fifth, AHPs would have to offer comprehensive benefits packages to cover all reasonably necessary and appropriate services commonly found in robust private health care insurance.

Access to health care is impeded by many financial and non-financial barriers under the current system. The federal parameters described above would not eliminate many non-financial barriers. However, the reform bill would facilitate access to a large number of people who are currently denied care because they cannot afford to pay for premiums or services.

The goal of universal access to health care may be significantly compromised as the bill goes through Congress. It is clear that bringing the currently uninsured into the system will be expensive, probably involving $\$ 50$ billion or more in annual expenditures. There will certainly be a period of time within which there would be a phased introduction to the new system. "Phasing in" of the uninsured within a specified brief period is critically necessary to ensure their full inclusion in the new system. If the phase-in period is contingent on achieving cost savings or is indefinite in duration, the poor would be vulnerable to changes in government and efficiency failures in the new system.

The structuring of the federal subsidy for the uninsured is equally important to achieving the goal of universal access. If the subsidy is too low, many individuals will continue to find health care unaffordable. For example, a sliding scale that would provide persons at 50 percent of the poverty level with a full subsidy and those at 100 percent of the poverty level with no subsidy would leave many individuals out of the new system. Worse still, an inadequate subsidy might compel a problematic choice for the poor between joining a system that they cannot afford and violating the law that would require enrollment of all citizens and lawful residents.

\section{Equity}

An equally compelling goal for the new system is to distribute the benefits of health care equitably. A two-tier system of health care, in which poorer people in the lower tier receive clearly inferior and lower quality services, perpetuates inequities among individuals and groups. The proposed health care plan would limit inequities by treating all persons, regardless of economic status, alike in fundamental ways. All individuals would receive the same health security card, be eligible to enroll in any health plan, and have access to the same health benefits package. The risk, however, is in structuring a system in which significant differences in cost exist among health plans, in which poorer people can afford only to enroll in the lowest priced, or benchmark, plan. Even though all plans would offer the same package of benefits, the added revenue and middle class consumer insistence on high quality and broad choice will drive the richer plans to offer more health care professionals with better qualifications and experience, more sophisticated machinery, and shorter waiting times for services.

Ideally, poorer individuals would be fairly distributed among all plans. This might be achieved in several ways, although society probably will not remove all inequities. A new system could be designed to limit the differences in price between the lowest and highest cost plans within health alliances (a concept called "banding"). For example, the highest cost plan might be prohibited from charging people more than 20 percent over the benchmark plan. The system could also subsidize poor populations generously so that individuals could afford to enroll in higher cost plans. A subsidy of, say, 120 percent of the benchmark level would enable low income consumers to choose from a variety of AHPs. Finally, the government could regulate AHPs to require all to accept a certain percentage of low income consumers. If the federal statute does not seek to reduce inequalities in these or other ways, a serious potential exists for considerably different standards of care between rich and poor consumers.

\section{Justice}

A just health care system would incorporate both substantive and procedural aspects of justice. A substantively fair health care system would distribute benefits based primarily on need for services, and distribute burdens primarily on the ability to pay. The requirement for community rating with the absence of pre-existing condition clauses or caps on coverage helps assure a needsdriven system. Progressive taxation would best distribute the burdens of paying for health care. A financing system based on a percentage of payroll, for example, would be progressive, requiring those employers and employees in higher wage industries to pay more.

A procedurally fair system would put in place impartial, speedy, and effective mechanisms for review of the grievances and complaints of consumers. Denials of care would not be unilateral decisions of non-physician managers, but would be subject to review at the initiative of the health care professional and/or patient. Alternative 
dispute resolution at the plan level, fair hearings at the health alliance level, and speedy access to the courts would all help assure a procedurally just system that respected the rights of informed consumers.

\section{Choice}

For many consumers and physicians, the concept of "choice" has become a yardstick with which to measure a new health care system. Protecting and enhancing individual choices are essential to respecting consumers as autonomous agents. The term "choice," however, is often oversimplified in health care debates. It is often used unidimensionally to mean choice of physicians. The health care reform bill will probably protect choice by giving individuals the right to enroll in the plan that has his or her preferred physician. If the physician moves to another AHP, the consumer could also move. Those seeking a truly unconstrained choice among providers could enroll in a fee-for-service plan.

To be sure, a new system would probably constrain many consumers from choosing whatever doctor they wanted. However, "choice" is a multidimensional concept. The new system would give increased "choice" to receive health care for persons who previously could not afford health insurance. It also would provide a greater range of health plans for consumers to choose from in many areas of the country. At present, many employers are strictly limiting the health plans workers can choose from.

\section{A "New Deal" for health care}

The years 1993-1994 may produce the most important domestic social reform since the New Deal. Health care reform, if reasonably structured, can produce enormous social good for millions of Americans by enhancing their access to care, reducing inequities in the health care system, allocating benefits and burdens more justly, providing substantive and procedural due process for consumers, and expanding choice along several dimensions.
In deciding whether to support the Presidential health care reform package, the public should carefully measure the design features of the Bill against these standards. As years of careful thinking and writing on health care reform turn into a season of political debate and decision, the ethical dimensions regarding the value of health care in the daily lives of Americans need to be carefully weighed.

\section{References}

1. See, e.g., Steffie Woolhandler \& David U. Himmelstein, "A National Health Program: Northern Light at the End of the Tunnel," JAMA 262 (1989): 2136; Kevin Grumbach et al., "Liberal Benefits, Conservative Spending," JAMA 263 (1991): 2549; Paul D. Wellstone \& Ellen R. Shaffer, "The American Health Security Act - A Single-Payer Proposal," New Eng. J. Med. 328 (1993): 1489.

2. See, e.g., John D. Rockefeller IV, "A Call For Action: The Pepper Commission's Blueprint For Health Care Reform," JAMA 265 (1991): 2507; see also Gen. Acct. Off., Access to Health Care: States Respond To Growing Crisis 32-35 (June 1992) (describing the 1988 Massachusetts "pay or play" system).

3. Lawrence Gostin, "Foreword: Health Care Reform in the United States: The Presidential Task Force," Amer. J. Law of Med., 19, No. 1-2 (1993).

4. BNA, "Number of Uninsured Persons Increases to 36.6 Million in 1991," Daily Labor Rep., Jan. 121993.

5. Paul H. Wise, et al., "Racial and Socioeconomic Disparities in Childhood Mortality in Boston," New Eng. J. Med., 313 (1985): 360, 364.

6. Council of Ethical and Judicial Affairs, "Black-White Disparities in Health Care," JAMA, 263 (1990): 2344.

7. John Z. Ayanian, Arnold M. Esptein, "Differences in the Use of Procedures Between Women and Men Hospitalized for Coronary Heart Disease," New Eng. J. Med., 325 (1991): 221-225.

8. Norman Daniels, "Just Health Care" (1985).

9. Sally T. Sonnenfeld et al., "Projection of National Health Expenditures Through the Year 2,000," Health Care Fin. Rev., (Fall, 1991), at 1, 4, 22; Congressional Budget Off., Projections of Health Expenditures 14 (Table 1) (Oct., 1992).

10. George J. Schrieber et al., "Health Care Systems in Twenty-Four Nations," Health Aff., (Fall, 1991): 22; Timothy S. Jost and Sandra J. Tanenbaum, "Selling Cost Containment," Am. J. Law or Med., 19 (1993).

11. Alain C. Enthoven, "The History and Principles of Managed Competition," Health Affairs, vol. 12, suppl. 1993 (1993): 24-48. 